\title{
Improvement of the gear production process by automating their strength calculations
}

\author{
Jacek Pacana' ${ }^{1}$ Andrzej Pacana' ${ }^{\text {, Lucia Bednárová2* }}$ \\ 1 Rzeszow University of Technology, The Faculty of Mechanical Engineering and Aeronautics al. Powstánców Warszawy 8, 35-959 Rzeszów \\ 2Ekonomická univerzita v Bratislave, Podnikovohospodárska fakulta v Košiciach, Tajovského 13, 04130 Košice
}

\begin{abstract}
The study presents the creation process and the effects of the calculation script for the bevel gear. The designed script has been prepared with the Python language editor program within the Abaqus software, applying the finite element method (FEM) for the calculations $[6,7]$. Its mission is to significantly improve the process of design and testing of the implemented product. Therefore it allows to shorten the manufacturing process and to improve the quality of the product. The prepared script works in such a way, that after importing properly prepared cogged wheel models from any CAD software, the entire process of defining and carrying out the calculations, as well as presentations of selected results is made automatically. This is particularly important in the case of the analysis comprising a large number of models of similar construction.
\end{abstract}

Keywords: FEM, Python, design, testing

\section{Introductory information}

The production process of gearing is a complex task, and it is often a timeconsuming operation. Particularly important is the initial stage, including the design and verification of the project. It can be conducted analytically, or more and more frequently, with the use of numerical analysis methods, with application of FEM as well $[4,5]$. Often, in order to find the optimal shape of the gear, similar operations, connected with e.g. defining new geometrical models and performing numerical calculations by FEM for similar design solutions, have to be frequently repeated. In this study the process of creation and application of the script in Python language for the Abaqus software was presented [1]. It supports numerical calculations of the bevel gears significantly accelerating the design process.

\section{Basic information about the Python}

Python [2] is a modern programming language with an exceptionally broad range of applications. It can be used for procedural programming, object-oriented programming, and programming in the functional style as well. It is one of the most readily used, scripting programming language that runs correctly on both the Windows platform, as well as on other Unix systems. This popularity results also from its advantages highlighted by the users, indicating at its versatility, such as [8]:

- Portability - works on almost all operating systems.

- Integration - may be run on any Java platform, to be integrated with objects. NET and COBRA, as well as to include a code in C and C ++ languages.

- Simplicity - it is easy to get started with Python, a clear and readable syntax facilitate creating applications. 
- Features - new enhancements are constantly created, concerning for example an access to databases, audio and video editing, or creating websites.

- Flexibility - is one of the most flexible languages enabling to solve problems related to the design and programming,

-Open-source - is the language of an open source code, so it may be easily distributed and used for free.

Python language may be integrated with other more advanced programs. In the Abaqus program, the scripts prepared in Python may be opened directly in the "Start" window, or by selecting from the top menu: "File/RunScript". Scripts must be written accordingly to the syntax of Python with the use of Abaqus software commands. Scripts may be also created directly in the Abaqus program, by using Abaqus PDE editor. The editor enables to create, verify and launch scripts in the main window of the Abaqus program.

The editor supports the appropriate formatting of lines of code, and additionally has the option to colour syntax. Abaqus PDE editor window with the visible fragment of the script concerning the preparation of bevel gear models for the FEM calculations is shown in Fig. 1.

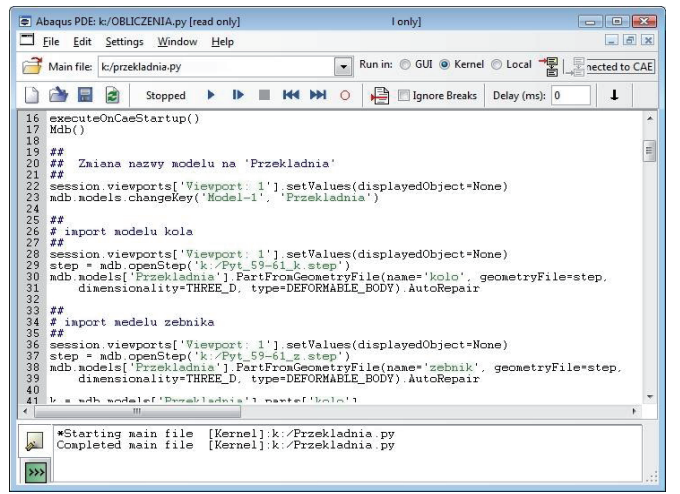

Fig. 1: View of the Abaqus PDE editor window.

The following presents a description and sample fragments of the script facilitating the preparation of the calculation model of the bevel gear for strength calculations. The script operation includes functions enabling to automatically import cogwheel models, define the material parameters, restraints and wheel load, create assembly, perform digitization of models, determine the contact surfaces and prepare the input file for the calculations in the solver. The entire script in Python language, including abovementioned actions, was prepared in Abaqus PDE editor. Below, there is a script block used for defining the bevel gear load.

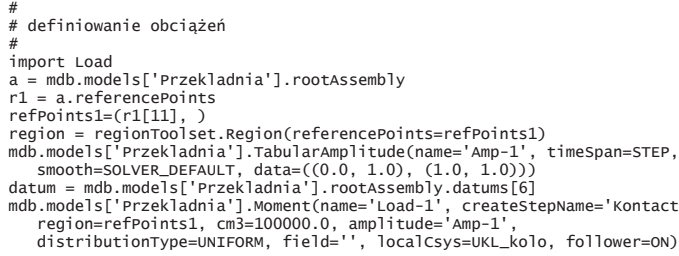

Defining the gear load is held in the "Load" module, which is activated by a command in the first row, below the comment. In the reference point of the cogged wheel ("refPoints1"), the load was defined by the torque value of $100 \mathrm{Nm}$, operating from the calculation step - "Contact".

Torque value from the beginning of this step until its ending is constant, which is established by the formula: data $=((0.0,1.0),(1.0,1.0))$.

After defining the entire model, and its acceptance, the batch file is obtained, on the basis of which the Abaqus solver commences the calculations.

The effect of the execution of all the commands of the script prepared in Python language, in the pre-processor of the Abaqus software, is shown in Fig. 2.

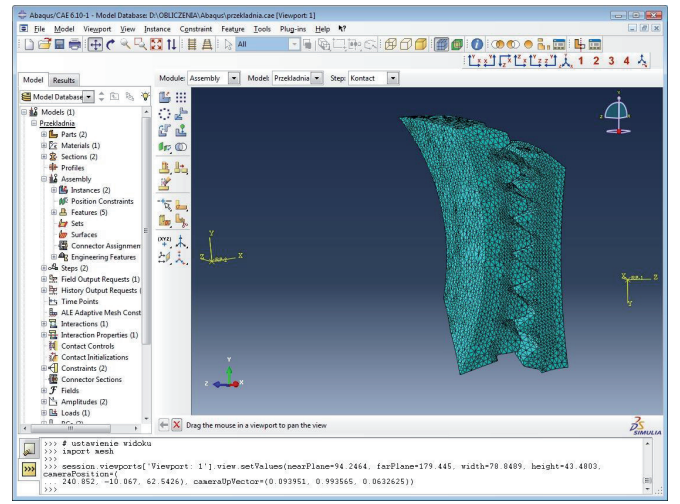

Fig. 2: Abaqus software window and the calculation model of the bevel gear ready for commencing the calculations.

\section{Object script developing}

The object file of calculations may be opened in the postprocessor of the Abaqus software, and the analysis of the results may be carried out in the "Visualization" module. The processing 
and interpretation process of the results may be improved through its automation, as well as the preparation stage of computational models. In this case, an appropriate script was also developed in Python language, and is responsible for opening the proper output file, appropriate configuration of the view window, selecting a desired type of results, and other possible actions requested by the designer. A sample script block is presented below.

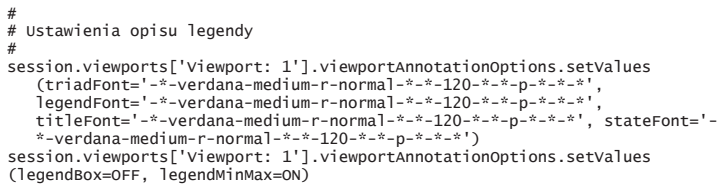

As a result of the developed script, different results may be presented on a computer screen. Below are presented the solutions for bevel gear wheels concerning reduced stress, and a trace of contact.

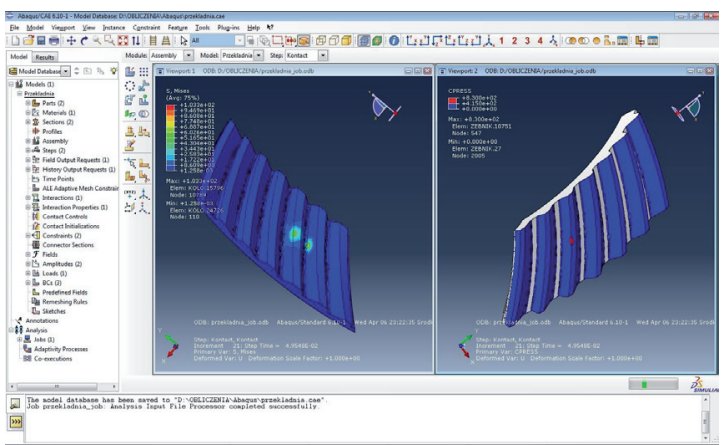

Fig. 3: Abaqus software postprocessor window view with the results for reduced stress and momentary contact trace.

Other possible solutions, obtained as a result of the script operation, these are, presented in the Fig. 4, summary traces of cooperation for the pinion model of the analysed bevel gear.

The script presented above may be freely modified and extended, depending on what kind of results are requested in the conducted analysis [3]. Only selected graphic functions were depicted, however it may also be used to create graphs or simulation of the working gear in the form of animation.

\section{Summary and Conclusions}

This study presents the creation process and the effects of the script, due to which it is possible to automatically prepare and execute numerical calculations with FEM for the bevel gears. This



Fig. 4: Postprocessor window view of the Abaqus software with automatically obtained results concerning the summary traces of cooperation for the pinion.

is particularly important in the case of analysis embracing a large number of models that differ only in minor details. Created script is launched in Abaqus calculation software with built-in editor and interpreter of the Python code, in which it was written. Two separate scripts were prepared: the calculative one and the target one, due to which the extent of necessary actions of the designer performing numerical calculations of the bevel gear were significantly limited.

Calculation script is developed in such a way, that previous preparation of the gear wheel models in any CAD software is succeeded by importing them to the pre-processor of the Abaqus program, in which, in an automated manner, other data for the calculations are defined. In addition to the geometry, boundary conditions and restraints, the software automatically determines the rotation angles and the transmission load. Finally, the script is preparing the input file for the calculation and launch it upon approval of the operator.

The object script retrieves the results for the analysed models, received in the calculating solver, and automatically displays them along with corresponding distribution of the reduced stress. However, this form of presentation of the results is usually insufficient, therefore, the developed script provides the adjustment of the output window display parameters to the desired form. The main task performed by the script, equally developed in Python language, is to present the solutions for the contact trace on the side surfaces of the teeth. The procedures were developed to ensure, that 
in the view of the Abaqus software postprocessor there are displayed in sequence: temporary contact trace for the particular calculation step, then the summary trace of cooperation for bevel gear wheels. Especially the last action of the script greatly facilitates the processing and analysis of the results, improving the process of selecting, among many options, the most beneficial shape of the teeth.

By using traditional methods of optimizing the conditions for cooperation, it would be necessary to perform physical models of multiple pairs of wheels, differing only in selected parameters. In the case of executing the numerical analysis using Abaqus software, with the application of the developed script, the entire process converges to the preparation of virtual models, saving them in a universal exchange format, e.g. *.STEP, and afterwards running the prepared script. In necessity of applying the presented script to another type of gear, each of the process steps may be edited by changing the individual functions or parameters directly in the Abaqus software.

\section{References and Notes}

[1] Abaqus 6.8-3 - Podręcznik użytkownika.

[2] Dayley B.: Python. Rozmówki. Wydawnictwo Helion S.A. Gliwice 2007r.

[3] Delyová I., Sivák P., Trebuňa F., Hricová B.: Influence of Material Structure and its Properties on Predicting Life of Pressure Pipelines. Applied Mechanics and Materials. Vol. 611 (2014).

[4] Pacana J., Budzik G., Kudasik T.: Wyznaczanie naprężeń zginających w kołach zębatych z zastosowaniem metody elementów skończonych. Acta Mechanica Slovaca 3-A/2008, PRO-TECH-MA Ročnik 12, Kosiče 2008r.

[5] Pacana J., Pacana A., Bednarova L.: Strength Calculations of Dual-power Path Gearing with FEM. Acta Mechanica Slovaca Vol ume 18, No. 2/2014, Kosiče 20014r.

[6] Rakowski G., Kacprzyk Z.: Metoda Elementów Skończonych w Mechanice Konstrukcji. Oficyna Wydawnicza Politechniki Warszawskiej, Warszawa 2005.

[7] Rusiński E., Czmochowski J., Smolnicki T.: Zaawansowana metoda elementów skończonych w konstrukcjach nośnych. Oficyna Wydawnicza Politechniki Wrocławskiej, Wrocław 2000

[8] Summerfield M.: Python 3. Kompletne wprowadzenie do programowania. Wydanie II, Wydawnictwo Helion S.A., Gliwice 2010.

\section{Biographical notes}

Andrzej Pacana, DSC, PhD, Eng., associate Professor of the Rzeszów University of Technology. He is working in the Department of Technology and Production Engineering, at the Faculty of Mechanical Engineering and Aeronautics of the Rzeszów University of Technology. Author or co-author of 23 books and approx. 230 scientific papers published in national and international journals and presented at conferences. His scientific research interests include issues on: quality management systems, environmental and safety labor, logistics and quality engineering.

Jacek Pacana, PhD, Eng., is a graduate of the Faculty of Mechanical Engineering and Aeronautics at the Rzeszów University of Technology. After graduation he worked in industry, and currently he is employed at the Department of Machine Design at the Faculty of Mechanical Engineering and Aeronautics of the Rzeszów University of Technology. His scientific research interests include issues related to the use of CAD / CAM /CAE methods in designing and mechanical design calculations, and gears in particular. His works within this scope were published in national and international journals and presented at many scientific conferences.

Lucia Bednárová, doc. Ing., PhD., she is working as an Associate Professor on University of Economics in Bratislava, Faculty of Business Economy with seat in Košice. Author or co-author of 10 books and approx. 120 scientific papers Publisher in national and international journals and presented at conferences. Her scientific research interests include issues on: environmental and safety labor, logistics and process management. 